This is an accepted manuscript of an article published in the International Journal of Media \& Cultural Politics, available online: http://dx.doi.org/10.1386/macp.10.3.301 1

\title{
Scholar-practitioner collaboration in media-related interventions: A case study of Radio La Benevolencija in Rwanda
}

\author{
By Lauren Kogen, Temple University, and Monroe E. Price, the Center for Global \\ Communication Studies
}

\begin{abstract}
What methodological, ethical or other issues arise in 'media development' projects that are collaborations between practitioners and scholars? This article uses as a case study a project led by Radio La Benevolencija (RLB) that sought to address interethnic conflict in Rwanda through a radio drama programme - a Romeo and Juliet story of a forbidden love between members of two conflicting tribes. The intervention was unique in its attention to theories of communication and psychology in its design and implementation, and in its efforts to bring in academics throughout the course of the project to aid in design and evaluation. The authors, commissioned to conduct an evaluation of RLB's past ten years of work, analyse the intervention in the context of Rwanda's history and the organization's use of theory, research and evaluation in their programmes. The authors find that, based on the RLB experience as well as evidence provided by communication and media research, the RLB model for peacebuilding through the media can be usefully adapted to other contexts, given particular parameters. The article concludes by arguing that the collaboration provides evidence of the fruitful ground that can and should exist between practice, theory and research, while problematizing challenges involved in such collaborations.

In context after context, the irresponsible use of media has hardened antagonisms; at times it has nourished wild storms of genocidal activity. Media scholars play a role in investigating these processes of incitement. In this essay, we look at a Rwanda-based case study where uses of media deepened hate with world-shaking consequences and, in the wake of disaster, practitioners, governments, funders and scholars worked together in processes of repair and restoration. It is the aspect of collaboration in the difficult process of healing that attracts us. Our case study is an effort that persisted for a decade (and continues), and one that is distinctive because of its grounding in theory, with a deep set of psychological justifications. We do not enter the debates about the relationship between peacebuilding and transitional justice: whether advancing one, for example, hinders the opportunity for the other (Sriram et al, 2013). The Rwanda intervention we describe here deals more fundamentally with changes in underlying attitudes and how theorizing about that subject influenced practice (and how involvement in practice influenced research). What we do here cannot be exhaustive, but we hope it sparks further discussion about these interrelationships.
\end{abstract}

\section{Background}

The story of Rwanda and the mass murders there has been oft-told, and with it the story of the role of media in shaping conflict-related attitudes (Gourevitch, 1999; Straus, 2007). In the 
wake of the genocide, indeed, emerging before, two separate literatures can be identified.

One portion of the literature emphasizes how media can and do play a potentially divisive role both during conflict and in the post-conflict era (Thompson, 1994). Studies emphasized how narratives regarding past conflict tied to ethnicity and identity can be intensified by media representations, undermining efforts to reconcile groups (Glaser, 2000; Ross, 2004). Media can be a site for the playing out of "culturally meaningful rituals and symbols [that] emphasize differences between communities, contain negative images of the other community, or evoke strong opposite reactions from each community" (Ross, 2004: p. 1018). Media, especially media sponsored by special interests, political parties, or government factions, often seize on polarizing myths as a mode for retaining their loyal following, often subverting the possibility of more peace-oriented narratives. Media, pervasive and absorbed, can reinforce the persistence of divisional identities, especially when there are efforts to deploy ideology to surmount existing settlements of identity politics. Media advance or minimize the impact of harmful symbols in adjusting social relationships.

Running through these studies is a common denominator: there are deeply embedded markers of hate - hate for which collective memories - accurate or not - can be summoned; hate that is the consequence of long-endured perceptions of dominance and oppression; hate that is the consequence of differences branded as ethnic with a construct of attitudes toward the other that is hard to jar or modify. Embedded hate often leads to physical divisions such as partitions and movements of populations, sometimes involuntary ethnic cleansing, sometimes partition by agreement and the redrawing of national lines.

In a second portion of the literature, less abundant, scholars study how the media play a specific role in certain transitional justice mechanisms, and in healing and reconciliation. Transitional justice efforts are wide-ranging with hoped-for impacts on populations and their behaviors. Some of the most publicized transitional justice measures - here defining the concept very broadly - include truth commissions, large-scale reparations programs for victims, and prosecutions of the architects of the crimes. These measures may be undertaken by various actors, including local communities, national governments, NGOs or international bodies.

In these processes, media contribute to determining how issues of healing, reconciliation, and rebuilding are articulated for public audiences, what (if any) kind of societal consensus might take place, and which of many competing objectives may be achieved. A diverse media system can allow different parties to discuss issues and air grievances, can force leaders and politicians to be held accountable for their actions, can facilitate reconciliation by providing an outlet for citizens themselves, and can present ideas and possibilities regarding promotion of reconciliation and ways to move forward after a conflict (Price \& Thompson, 2002; Ramsbotham, Miall \& Voodhouse, 2011; Wolfsfeld, 2004).

This divide within the scholarly literature illustrates that, while media practices may perversely exploit interventionist opportunities to deepen ethnic divides, they may, conversely, support and advance efforts to knit a society together. Intervening actors need to consider how to engage with the media to establish a supporting environment for reconciliation measures. They can help address questions of responsibility, define competing perceptions of justice, and in some circumstances provide a forum for their negotiation.

Scholars of communication have been long interested in this field of intervention to reduce conflict-related attitudes. Some have dealt with issues of norm creation in the field of hate speech (Hare \& Weinstein, 2009), and a science of intervention through education and efforts to alter basic attitudes, beliefs and behaviors has developed (e.g., Ajzen \& Fishbein, 2005; Cappella 
et al, 2001). Political and legal approaches are supplemented by more deep-seated efforts to tap underlying aspects of identity. Some of this work has been rooted in experiments in "edutainment" (though most edutainment work in international settings continue to focus on health programs). Susan Benesch (2012) and others have experimented with ways of characterizing and moderating what she calls "dangerous speech." There is a long history of transnational efforts at conflict reduction between ethnic groups when such scenarios arise (Price \& Stremlau, 2012).

As toolkits for constructively employing media in post-conflict contexts expand, it is useful to think whether scholars of communication have a special role (perhaps even responsibility) in these divisive circumstances. There has been an increased effort in the past decade to meet this need. The work of BBC Media Action, highly evidence-based, is a stunning example (for instance their Indian television program designed to change knowledge and attitudes regarding HIV, Jasoos Vijay). But the majority of work in this area is still siloed - with theoretical work completed by scholars, and the implementation of interventions taken on by local and international NGOs or government practitioners.

\section{Radio La Benevolencija}

In this essay, we seek to parse how collaboration between media effects scholars and field practitioners can yield mutual benefits in the area of peacebuilding. To do this, we turn to a case study treatment of Radio la Benevolencija (RLB). RLB is an NGO based in Amsterdam. Its roots lie in the Balkan conflicts of the 1990s with a focus on Sarajevo and Bosnia-Hercegovina. In those bitter conflicts, with many people locked, geographically, in environments of destruction and hate, the antecedents of RLB formed. La Benevolencija Sarajevo, the predecessor to Radio La Benevolencija, had its origins largely in the Sephardic community in Bosnia Hercegovina, preoccupied with saving lives in the local population and facilitating exit for a substantial number of those trapped in war. After the Dayton Accords, George Weiss founded Radio La Benevolencija. He had been a volunteer with the Sarajevo group and, while there, had the idea for a non-polarizing way to make conflicting Yugoslav parties talk to one another by discussing the role of propaganda in the rise of the Nazis. Weiss and the leadership of RLB then searched for new areas of commitment to engage in peacebuilding and transitional justice. Rwanda became a demanding site to think through how media interventions could be used to reduce inter-ethnic animosity and promote post-conflict healing. What came to be RLB's extensive work in Rwanda was funded by the Dutch and Belgian Embassies in Rwanda.

The RLB intervention. Assisted in its initial effort by scholars investigating the reduction of intergroup conflict, RLB developed a program which would use the media to promote healing and forgiveness, and used a scientific approach to peacebuilding such that the intervention could be tested in a post-conflict setting. This project, ongoing for over a decade, offers what is perhaps the longest continuously monitored intervention of this type. The wealth of data available from the organization's evaluations and reports offers a rare opportunity to assess how media interventions in conflict-affected areas function over time, and how the RLB model might be adapted to other contexts. We believe this, in addition to the fact that the project represents a synthesis of frameworks from governments, practitioners and scholars, suggests that the intervention offers a valuable collection of data for better understanding the role of media in peacebuilding. 
The authors came to be involved in this research when RLB commissioned the Center for Global Communication Studies at the University of Pennsylvania's Annenberg School for Communication to evaluate its past ten years of work. Armed with thousands of pages of proposals, reports and external evaluations, we began the difficult - but ultimately fruitful - task of analyzing the organization's work to date. Here, we describe the influence of scholar on practitioner and how academic theory was embraced in project design and implementation. This article provides a small portion of our findings and insights from an in-depth analysis of over ten years' worth (2003-2013) of documentation, including evaluations of the NGO's work by others.

At the heart of the theoretical design was the work of Dr. Ervin Staub, a highly respected psychology professor whose work examines the social processes that lead to mass violence and genocide. He was specifically enlisted for the RLB project to help RLB with their implementation design. Staub's theory about the circumstances that can lead to genocide posits that one strong influence involves what he calls, with some subtlety, the presence of "difficult life conditions." Those within this category suffer psychologically when their basic needs (security, feeling of control, positive identity, etc.) are unmet (Staub, 2012a). Under such conditions, some may attempt to meet their own psychological needs in ways that are destructive: that is, their efforts to fulfill their own needs interfere with the psychological wellbeing and needs of others. This destructive behavior begins with the formation of in-groups, and leads to the scapegoating of other groups in order to lay blame for difficult conditions. The process, Staub posits, culminates in the creation of exclusive ideologies that promise a better future for the in-group at the expense of the out-group. If other contributory conditions are also present - the existence of identity groups, a very strong societal respect for authority, an autocratic political system, and a history of aggression or victimization - this increases the likelihood of an outbreak of mass violence.

Staub further argues that mechanisms exist to prevent or end this cycle. One is to increase socialization between groups, though this is hardly a guarantee of success. A more ambitious strategy is to develop the capacity for a critical consciousness within individuals. This concept forms the crux of the Staub - and, therefore, the RLB methodology. By teaching members of society to understand how destructive needs and actions arise - especially those that "can subvert moral thinking, feeling, and action" (Staub, 2012b: p. 394) - they are more likely to recognize the truth behind their own behavior before it develops into violence. By "understanding the influences that lead to mass violence," citizens can become self-aware in a way that will ultimately reduce violence (p. 394).

Staub's theories relate closely to those of Laurie Pearlman, another scholar involved in the initial design of the RLB project, whose research focuses on the healing process. Pearlman's work looks at the effects of adult trauma and the benefits of talking about traumatic experiences under safe conditions (see, for example, Staub, Pearlman, Gubin, \& Hagengimana, 2005). Some of Pearlman's work, including that in Rwanda, focuses on training others to be empathic listeners, so that these safe conditions can be created.

According to Staub and Pearlman's research, understanding how violence evolves aids the healing process for perpetrators of violence, who are more able to confront their own actions. It also provides victims of violence with a way to understand, at least to some degree, the actions of their perpetrators, resulting in more positive feelings toward the other group. Staub and Pearlman's research in Rwanda (e.g., Staub et al., 2005) supports this theory: in one controlled experiment, they found that training group facilitators to lead discussion groups about traumatic experiences not only reduced trauma but also increased positive feelings toward the perpetrator 
group. Their research provides solid rationale for trying to bring their work to scale through a media intervention that teaches the cycle of violence and the need for psychological healing and reconciliation.

The gacaca courts in Rwanda are a clear example of trying to use these two distinct avenues to promote reconciliation (Clark, 2010). These courts were designed to provide a swift and fair local system for dealing with the large number of perpetrators of genocide. Trials were held within the communities in which crimes occurred; judges were elected among the community members; and victims and even bystanders could attend the hearings. The gacaca system was premised on the idea that those whose families had been killed should forgive and pardon perpetrators for the sake of moving forward. Perpetrators were encouraged to admit their wrongdoings at the trials and seek forgiveness, and many did so. In a similar way, Staub and Pearlman's research illustrates the importance of trying to show victims how perpetrators might have come to engage in terrible acts of violence - to help victims understand the continuum of violence.

In the intervention examined here, such self-reflection is promoted primarily through a Rwandan radio drama, New Dawn, produced by RLB. New Dawn is a Romeo and Juliet love story of a forbidden love between members of two conflicting tribes. Lessons about the factors that lead to violence, encompassed in a list of 35 "messages" designed by the RLB team, are woven into storylines by the program's writing team. Roughly, these 35 messages fall into eight groups, including messages associated with the origins of violence, cultural characteristics that increase the likelihood of violence, how to prevent violence, the psychological impact of violence, and healing and recovery. In addition to the radio drama, RLB organized local grassroots discussion groups, discussed below, in which chosen members of a community were trained in the cycle of violence and prepared to serve as role models for others in their community. ${ }^{1}$

A central assumption of media campaigns is that audiences must receive sufficient exposure to the campaign if any impact is to be expected. New Dawn, still today an immensely popular program, easily meets such criteria. According to the last audience research survey commissioned by RLB, approximately $84 \%$ of Rwandans listen to the program regularly.

Over the ten years that RLB has been in the field thus far, they commissioned a variety of evaluations of the impact of New Dawn and its other programs. Overall, the evaluations support the general conclusion that edutainment can have positive effects on beliefs, attitudes, and behaviors. Significant changes in knowledge, attitudes, and behaviors were found for New Dawn listeners in 2005, 2006 and 2011 evaluations. Among some of the key findings, listeners were significantly more likely to have more trust in their community, not to advise their children to marry only according to social group membership, to have reasonable respect for authority, to believe that traumatized people are more likely to commit violence, to believe in the benefits of talking about trauma, to believe in the importance of having a shared view of history, and to have more positive feelings towards members of their out-group.

Further, the long-running series design of New Dawn allowed evaluators to uncover the interesting and important finding that greater exposure over time seems to lead to an increase in some effects.

\footnotetext{
1 RLB developed other programs as well to complement the radio and drama and the grassroots groups. RLB's corollary programs are not addressed here.
} 
Combining mass media and community efforts. There is a divide in the development world between practitioners who concentrate on mass media campaigns and those who focus on interpersonal, community-level interventions (Morris, 2003). While scholars and practitioners increasingly acknowledge the importance of bridging this gap, development interventions that do so are rare. The case of RLB's radio drama offers important insights regarding whether interpersonal interventions are a helpful corollary to mass media campaigns. In Rwanda, local community discussion groups were created to amplify the effects of the radio drama series. This additional intervention took two forms: 1) taking part in 'listener groups' that discussed the radio program, and 2) holding direct trainings of group members who could spread RLB's messages in their community both indirectly, by acting as role models, and directly, by passing on knowledge.

This design was substantially based on Staub and Pearlman's work on trauma healing through group discussion (Staub et al., 2005). Such emulative frameworks are well-rooted in communication and psychology research on role modeling (e.g., Bandura, 1991), though one conclusion from our evaluation was that these groups could have been more theoretically guided and the guidelines more consistently implemented. Providing a peer role model, in addition to the role models presented through the drama, offers an additional mechanism for reinforcing the attitudes and behaviors performed in the narrative.

Despite the fact that the impact of these discussion groups is still, in our opinion, in need of more rigorous evaluation, there is enough evidence to suggest that the groups did indeed amplify the impact of listening to the radio program. A focus group evaluation carried out for RLB in 2009, by Bert Ingelaere, a researcher at the University of Antwerp, found that approximately $70 \%$ of focus group participants cited visible positive changes in their communities due to the discussion group programs, and that the participants who were explicitly trained in the RLB methodology, in fact, became role models in their communities. The report additionally found that social cohesion increased, and knowledge about the continuum of violence and trauma healing increased.

The impact of RLB's community leaders, or what they called 'agents of change,' offers potential to build on role modeling theory. Some role models - such as opinion leaders, elites, and even celebrities - have been shown to be particularly effective in spreading knowledge, ideas, and attitudes. Some of the most well-known and oft-cited communication theory relates to ideas about how information and ideas spread. Katz and Lazarsfeld's two-step flow theory (1955) and Everett Roger's diffusion of innovation theory (1962) revolve around the idea that most people do not simply gain information from its original source (such as the media). Rather, ideas are spread through people. One influential person gaining a particular piece of information, or accepting a particular belief or attitude, can then go on to influence others, and so on. These ideas are crucial for understanding how media messages are spread, and how they ultimately influence the public. The idea that opinion leaders, influential peers and celebrities have an important role in spreading messages has been incorporated into much of the work on behavior change (Kelly et al., 1991; Valente \& Pumpuang, 2007). The fact that many of RLB's agents of change have become leaders in their communities, being sought out for advice and assistance, suggests that they are well positioned to spread the knowledge and ideas behind the show.

\section{Adapting the RLB method to other peacebuilding contexts}

One objective of our analysis was to determine how difficult it would be to adapt RLB's 
approaches to reconciliation and peacebuilding in contexts beyond Rwanda. It was difficult to root this inquiry in existing communications research. Looking for comparisons was complex. Estimates vary as to how many organizations are engaged in similar activities throughout Africa. ${ }^{2}$ The majority of peacebuilding programs there have project components that incorporate trauma healing, breaking the cycle of violence, reconciliation, or some combination of the three. Transitional justice programs, although present in most countries recovering from conflict, remain primarily the domain of specialized international NGOs with a legal background, not media-focused NGOs. Evaluations relate to their effectiveness on site, not necessarily how they adapted or were required to adapt to be effective.

Smaller NGOs with a media-specific mandate usually conduct standalone programs for peacebuilding journalism or conflict-sensitive journalism. Fondation Hirondelle has pioneered in peace broadcasting. To our knowledge, three organizations in Africa (Search for Common Ground, ALARM, and International Medical Corps) in addition to RLB, use narrative entertainment programming to promote peacebuilding. RLB and Search for Common Ground are singular in using such narrative entertainment as a core component of their framework.

RLB's overall design - in particular the combination of radio drama and grassroots discussion groups - was seen as having potential as a model for transfer to other contexts. Of course, the transfer of an intervention from one context to another is always a thorny endeavor. Evaluations of interventions often attempt to justify results as producing "external validity," indicating that findings can be applied outside the area of evaluation. This is often a difficult case to make when the evaluation area is unique in certain relevant respects. While many attempts have been made to produce recommendations for adaptations of specific programs - especially in the areas of education and health - only a small number of scholars have tried to codify general strategies for moving development interventions to new, unique contexts (e.g., Backer, 2001; Castro, Barrera, \& Martinez, 2004), though these do not refer to the field of peacebuilding or governance specifically. For example, Castro, Barrera and Martinez (2004), in their discussion of adapting interventions from one context to another, highlight the importance of matching both fidelity (maintaining the core aspects of the original intervention) and fit (making sure the new intervention is responsive to local needs). They highlight areas where programs tend to be mismatched, including language, ethnicity, family stability, and urban-rural context, among others. Backer (2001) sets out "twelve steps" to adapt a program, which include examining community concerns, determining needed resources, and determining what kind of training is available at the intervention location.

Other approaches rely less on the idea that "fit" can be achieved even with meticulous preparation, and focus more on a dynamic and iterative process that adapts the intervention continuously as new information arises. This information comes both from changing knowledge about the situation on the ground and the context of the problem attempting to be addressed, as well as from the organization's own evaluations of its work.

Our contribution as evaluating research scholars was to help assess which aspects of the RLB project were, in fact, adaptable elsewhere. Does RLB's experience produce "best practices" for reprocessing? RLB operated in Rwanda for a decade and had significant positive effects. But

\footnotetext{
2 Some organization addressing peacebuilding in Africa include African Enterprise International; ALARM; CARE International; Catholic Relief Services; CENAP, Concordis International; ICTJ; Institute for Research and Dialogue for Peace; International Alert; International Medical Corps; Interpeace; Karuna Center; Local Capacities for Peace International; Never Again Rwanda; PANOS; Peace Direct; Peter C. Alderman Foundation; Search for Common Ground; UN / UNDP / UNHCR.
} 
what can be said about practices of scalability and transfer? Were local political conditions necessary for implementation?

Rwanda is currently relatively stable, and there is support by the government and the public to seek ways to foster reconciliation. If anything, the government is almost coercive on the issue of reducing conflict. The gacaca trials indicate a national desire to heal and move forward, even if the outcomes of the trials were not as positive as optimistic expectations predicted. In addition, the country's small size makes an intervention designed to impact a large portion of the population more feasible. These circumstances were helpful, and distinguished Rwanda.

As indicated, the theories of Staub and Pearlman that form the backbone of RLB's work are encapsulated in the 35 "messages" that RLB seeks to impart to audiences. But these messages need constant scrutiny to adapt the Staub continuum to different contexts. The approach must be to deploy a flexible and organic tool, encompassing multiple routes to reduced violence. A prototype that is useful for scalability and adaptation to other contexts requires that it be theoretically rigorous, so that the ideas behind the model are sound and likely to be widely applicable, but also 1) that it be simple enough for other organizations to use, and 2) that it have enough moving parts to allow for modification based on context. Hummelbrunner and Jones (2013), of the Overseas Development Institute, note that in complex environments, "plans should be light and imaginative, as they are primarily communication tools between involved actors. The formats should allow rapid up-dating, visualize complex situations and suit a broad, heterogeneous group of actors" (p. 5).

\section{Conclusion}

Research scholars enriched RLB's practice, and RLB's large scale experiment was enriching to scholars. RLB, its origins, and its activities in Rwanda provide a major example of a carefully supported structured intervention. For the past decade that RLB has worked in Rwanda - and then in Burundi and the DRC - it has provided citizens with tools for healing trauma and recognizing and resisting manipulation to violence. Using a combination of edutainment methodologies and comparative psychological research, RLB's media interventions in Rwanda, Burundi, and the DRC sought to embed, in national audiences, knowledge of how to resist the psychological pressures and demagoguery that, according to RLB's research, turn individuals into perpetrators of mass hate.

The combination of rich theory with commitment to practice meant that RLB had a singular position within the field of peacebuilding in the Great Lakes region. It has been among a tight cohort of entities working to use popular media to address divisions, perhaps the only organization working to do so through a psychology-based lens (and systematically deploying theory to help journalists and audiences understand the origins and dynamics of such speech). It is one of a handful of organizations doing such work through narrative entertainment in the region. By emphasizing the psychology behind violent acts, RLB helps audiences understand what makes us human, and how the humanity of a community can ignite its own healing.

The RLB case study also furnished insight into ways research scholars, dedicated to understanding the impact of messages on attitudes, beliefs and behavior, could engage in the process of constructive intervention. By partnering with scholars, RLB served to help the research community, practitioners and funders better comprehend the role of media in peacebuilding and transitional justice. They are hardly alone; perhaps this anniversary issue of 
the Journal can spark more - and more theoretically rigorous - attempts to conceptualize and concretize the role of media in peacebuilding, transitional justice and governance. Practitioners, NGOs and scholars currently engaged in this difficult work must seek out opportunities to adapt previous models in new contexts. By using media theory as a backbone to such work, but maintaining flexibility, an important research agenda can be advanced.

RLB's origins in Sarajevo provided it with a special "mission" to encourage understanding across major differences. There was a special resonance between its approach and the scientific-based theories of a particular theoretician, here Dr. Ervin Staub. A historic, idealistic commitment drove the core principles. It was unusual in its combination of background and orientation. Indeed, this seems to be a characteristic of several of the major players in the field (like Search for Common Ground and Fondation Hirondelle).

New questions constantly arise: What is the structure of governance in the 'target society' that allowed external interventions to take place and embed themselves? Was a necessary condition for RLB's work the support of President Kagame, and how did the work of RLB fit with Kagame's own political goals and objectives regarding reconciliation and divisionism? How is the role of funders changing? How do they see the research in their own construction of transitional justice, peacebuilding and the role of change in basic attitudes and beliefs? Research and field interventions do not take place in a vacuum. How effective are evaluation efforts at reshaping the work that is being evaluated? Are there ways of intensifying these kinds of interventions pre-conflict?

And then there are the questions relevant to the role of scholars and their cooperation in these media interventions. The closely joined efforts of RLB and the scholars who worked with them was exemplary. But is the time schedule of practitioners compatible with the patterns of academic scholars? Does the kind of collaboration described here fit well within the conventional, American tenure system or is it more suitable for scholars at research centers or institutes? Do evaluative processes have built in political imperatives or grids of performance that may fit the university environment only roughly?

The case study of RLB in Rwanda helps point to these questions and helps provide approaches to answers. It reaffirms how rewarding cooperation between practitioners and scholars can be in the too-abundant area of post-conflict healing of societies.

\section{References}

Ajzen, I., \& Fishbein, M. (2005), 'The influence of attitudes on behavior', in D. Albarracín, B. T. 
Johnson, \& M. P. Zanna (Eds.), The handbook of attitudes, Mahwah, NJ: Erlbaum, pp. $173-221$.

Arsenault, A., Himelfarb, S., \& Abbott, S. (2011), 'Evaluating Media Interventions in Conflict Countries: Toward Developing Common Principles and a Community of Practice', US Institute of Peace, Peaceworks No. 77.

Bandura, A. (1991), 'Social cognitive theory of moral thought and action', in W. M. Kurtines \& J. L. Gewirtz (eds.), Handbook of Moral Behavior and Development: Volume 1: Theory, Hillsdale, NJ: Erlbaum, pp. 45-103).

Backer, T. E. (2001), 'Finding the balance: Program fidelity and adaptation in substance abuse prevention: A state-of-the-art review'. Rockville, MD: Center for Substance Abuse Prevention.

Benesch, S. (2012), 'Dangerous Speech: A Proposal to Prevent Group Violence', World Policy Institute, New York, 2.

Clark, P. (2010), The Gacaca courts, post-genocide justice and reconciliation in Rwanda: justice without lawyers. Cambridge: Cambridge University Press.

Cappella, J.N., Fishbein, M. Hornik, R., Ahern, R.K., \& Sayeed, S. (2001), 'Using theory to select messages in anti-drug campaigns', In R.E. Rice \& C.K. Atkins (eds.), Public communication Campaigns, Thousand Oaks, CA: Sage, pp. 214-230.

Castro, F. G., Barrera Jr, M., \& Martinez Jr, C. R. (2004), 'The cultural adaptation of prevention interventions: Resolving tensions between fidelity and fit', Prevention Science, 5(1), pp. $41-45$.

Glaser, D. (2000), 'The media inquiry reports of the South African Human Rights Commission: A critique', African Affairs, 99(396), pp. 373-393.

Gourevitch, P. (1999), Tomorrow We Wish to Inform You That We Will be Killed with Our Families: Stories from Rwanda, New York: Picador.

Hare, I., \& Weinstein, J. (Eds.). (2009), Extreme speech and democracy. Oxford: Oxford 
University Press.

Hummelbrunner, R., \& Jones, H. (2013), 'A guide for planning and strategy development in the face of complexity'. Background Note, Overseas Development Institute, London. Retrieved from http://www.odi.org.uk/sites/odi.org.uk/files/odi-assets/publicationsopinion-files/8287.pdf

Katz, E., \& Lazarsfeld, P. (1955), Personal influence, New York: The Free Press.

Kelly, J. A., St. Lawrence, J. S., Diaz, Y. E., Stevenson, L. Y., Hauth, A. C., Brasfiel, T. L., ... Andrew, M. E. (1991), 'HIV risk behavior reduction following intervention with key opinion leaders of a population: An experimental analysis', American Journal of Public Health, 81(2), pp. 168-171.

Morris, N. (2003), 'A comparative analysis of the diffusion and participatory models in development communication', Communication Theory, 13(2), pp. 225-248.

Price, M., \& Stremlau, N. (2012), 'Media and transitional justice: Toward a systematic approach,' International Journal of Communication, 6 (23), pp. 1077-1099.

Price, M. E., \& Thompson, M. (Eds.). (2002), Forging Peace: Intervention, Human Rights, and the Management of Media Space. Bloomington: Indiana University Press.

Ramsbotham, O., Miall, H., \& Woodhouse, T. (2011), Contemporary Conflict Resolution, (3 ${ }^{\text {rd }}$ Ed) Cambridge: Polity.

Rogers, E. (1962), Diffusion of Innovations. New York: Free Press of Glencoe.

Ross, M. H. (2004), 'Ritual and the politics of reconciliation', In Y. Bar-Siman-Tov (Ed.), From Conflict Resolution to Reconciliation, Oxford, UK and New York, NY: Oxford University Press, pp. 197-223.

Sriram, C. L., García-Godos, J., Herman, J., \& Martin-Ortega, O. (Eds.). (2013), Transitional Justice and Peacebuilding on the Ground: Victims and Ex-combatants. Routledge.

Staub, E. (1989), The Roots of Evil: The Origins of Genocide and Other Group Violence. Cambridge University Press. 
Staub, E. (2012a), 'The roots and prevention of genocide and related mass violence', in I.W. Zartman, M. Antsey \& P. Meerts (eds.), The Slippery Slope to Genocide: Reducing Identity Conflicts and Preventing Mass Murder, Oxford, UK and New York, NY: Oxford University Press, pp. 35-52.

Staub, E. (2012b), 'Psychology and morality in genocide and violent conflict: Perpetrators, passive bystanders, and rescuers', in M. Mikulincer \& P. R. Shaver (eds.), The Social Psychology of Morality: Exploring the Causes of Good and Evil, Washington D.C.: American Psychological Association, pp. 381-398.

Staub, E., Pearlman, L. A., Gubin, A., \& A. Hagengimana. (2005), 'Healing, reconciliation, forgiving and the prevention of violence after genocide or mass killing: An intervention and its experimental evaluation in Rwanda', Journal of Social and Clinical Psychology, 24(3), pp. 297-334.

Straus, Scott. (2007), 'What is the relationship between hate radio and violence? Rethinking Rwanda's “Radio Machete"”, Politics Society, 35(4), pp. 609-637.

Thompson, M. (1994), Forging War: The Media in Serbia, Croatia, and Bosnia-Hercegovina, London: International Centre Against Censorship.

Valente, T. W., \& Pumpuang, P. (2007), 'Identifying opinion leaders to promote behavior change', Health Education Behavior, 34(6), pp. 881-896.

Wolfsfeld, G. (2004), Media and the Path to Peace. Cambridge: Cambridge University Press. 